ECOLOGICA, Vol. 28, No 101 (2021), 36-42

https://doi.org/10.18485/ecologica.2021.28.101.7

Originalni naučni rad

UDC:502.2:677

\title{
Uticaj proizvodnje i prometa tekstila na životnu sredinu
}

\section{Impact of production and trade of textile on the environment}

\author{
Lazar Cvijić ${ }^{1}$, Ljiljana Stanković ${ }^{2}$, Aleksandra Pavićević3 \\ 1,2,3Fakultet za poslovne studije i pravo, Jurija Gagarina 149a, Beograd, Srbija \\ $1,2,3$ Faculty of business studies and law, Jurija Gagarina 149a, Belgrade, Serbia \\ Rad primljen: 03.12.2020, Rad prihvaćen: 17.02.2021.
}

Sažetak: Proizvodnja i promet tekstila - tekstilna, odnosno modna industrija su među vodećim zagađivačima životne sredine o kom se ne govori dovoljno dok podaci govore da su i radnici u proizvodnji tekstila izloženi opasnim hemikalijama i procesima opasnim po zdravlje, kao i krajnji korisnici. Od svih hemikalija proizvedenih širom sveta, približno 25 procenata se koristi u tekstilnoj industriji. Samo u tekstilnoj industriji, koja predstavlja preko 40 procenata globalne proizvodnja, Kina koristi oko 42 posto svetskih tekstilnih hemikalija. Privreda može da pomogne u smanjenju i zagađenja i potrošnje energije koju ova industrija stvara. Potrošači širom sveta koji imaju svest o štetnim uticajima ove industrije menjaju svoje navike i pridružuju se pokretu spora moda što direktno utiče na smanjenje njenih štetnih uticaja.

Ključne reči: zagađenje, tekstil, životna sredina, modna industrija, potrošači.

\begin{abstract}
Production and trade of textiles - textile, ie fashion industry are among the leading polluters of the environment, fashion industry - is one of the biggest polluters of the environment, which is not talked about enough, while the data show that workers in the production of textiles are also exposed to dangerous chemicals and processes dangerous to health and end users. Of all the chemicals produced worldwide, approximately 25 percent are used in the textile industry. In the textile industry alone, which accounts for over 40 percent of global production, China uses about 42 percent of the world's textile chemicals. The economy can help reduce both the pollution and energy consumption that this industry generates. Consumers around the world who are aware of the harmful effects of this industry are changing their habits and joining the slow fashion movement which directly affects the reduction of its harmful effects.
\end{abstract}

Keywords: pollution, textiles, environment, fashion industry, consumers.

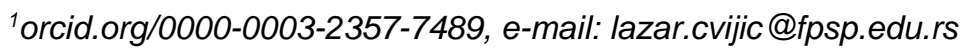

2orcid.org/0000-0001-6465-4693, e-mail: lilijana.stankovic@fpsp.edu.rs

3orcid.org/0000-0001-9493-272X, e-mail: aleksandra.pavicevic@fpsp.edu.rs 


\section{UVOD / INTRODUCTION}

Auto i avio saobraćaj, hemijska i petro-hemijska industrija i termo-energetska postrojenja se najčešće navode kao najveći zagađivači vode i vazduha, uopšte životne sredine. Međutim, i proizvodnja i promet tekstila- tekstilna, odnosno modna industrija je jedan od najvećih zagađivača životne sredine o kom se ne govori dovoljno ili nije dovoljno istaknut. Podaci govore da su i radnici u proizvodnji tekstila izloženi opasnim hemikalijama i procesima opasnim po zdravlje, a da su ugroženi i krajnji korisnici jer dolaze u kontakt sa štetnim materijama ugrađenim u proizvod. Tekstilna industrija je veliki potrošač energije, a posebno je veliki zagađivač voda jer se većina hemikalija i pomoćnih sredstava ispušta u otpadne vode.

Veliki su problemi i u informacionim tokovima $u$ odevnom sektoru s obzirom na negativne uticaje na životnu sredinu, društvo i zdravlje izazvane proizvodima / proizvodnim metodama u lancima vrednosti tekstila. Često nema dovoljno informacija o tome odakle i ko proizvodi, transformiše i sastavlja materijale što stvara nedostatak transparentnost $u$ pogledu uticaja praksi i procesa na životnu sredinu i zdravlje ljudi, što zajedno sa nedostatkom transparentnosti uslova rada u lancu snabdevanja stvara ključne probleme.

Koji su najznačajniji uzroci ovakvih uticaja prometa tekstila, odnosno modne industrije? Kakvi su problemi kod proizvodnje i prerade, a kakvi kod potrošnje? Šta može da uradi tehnologija, šta privreda, a šta pojedinac? Da li promena svesti kod potrošača o uticajima ove industrije i životnom ciklusu odevnih predmeta može uticati na smanjenje lošeg utiacaja na životnu sredinu kada je tekstilna industrija u pitanju?

\section{MATERIJALI I METODE / MATERIALS AND METHODS}

\section{Prerada i promet tekstila i njihov uticaj na životnu sredinu / Textile processing and trade and their impact on the environment}

Dve glavne kategorije uticaja na životnu sredinu proizvodnje i prerade tekstila su ispuštanje zagađujućih materija i potrošnja vode i energije (UNEP, 2011). Što se tiče ispuštanja zagađujućih materija, one mogu dovesti do zagađenja vazduha, vode i zemljišta i uglavnom su povezane sa upotrebom hemikalija. Međutim, dok su emisije u vazduh mali, ali ne i zanemarljiv izvor zagađenja, veliki je problem zagađenje voda, jer se većina hemikalija i pomoćnih sredstava ispušta u otpadne vode. Što se tiče organskog opterećenja, emituje se 20-100 g organskog ugljenika po kg prerađenog tekstila, što je 15-250 puta više od emisije u vazduh. Očigledno je da su emisije u vodu dominantne (www.oecd.org, 2004). Slučaj pamuka je posebno upečatljiv. Pamuk čini 45 procenata svih vlakana koja se koriste u globalnoj tekstilnoj industriji, a to uključuje rizike po zdravlje i životnu sredinu za farmere i ostale proizvodne prakse (Kaye, 2013). Većina operacija koristi visok nivo pesticida koji se mogu taložiti u tlu i vodosnabdevanju (www.kemi.se, 2014).

Proizvodnja i promet tekstila ima snažan uticaj na životnu sredinu, klimu i društvo. Tako odeća, obuća i tekstil za domaćinstvo zauzimaju četvrto mesto u korišćenju resursa vode (odmah nakon hrane, smeštaja i transporta), drugo mesto u korišćenju zemljišta i peto po količini emitovanja gasova sa efektom staklene bašte (greenfest.rs, 2020). Što se tiče potrošnje energije, poznato je da posao sa tekstilom igra ulogu u klimatskim promenama zahvaljujući svojoj značajnoj potrošnji energije. Da bi zadovoljio svoju potrebu za energijom, sektor pribegava dvema različitim vrstama izvora energije: indirektnim izvorima emisije (električna energija) i direktnim izvorima emisije (prirodni gas, kogeneracija - postupak za istovremeno generisanje električne energije i toplote. Takav način upotrebe znači da se iz iste količine goriva dobija, pored električne energije još i dodatne toplotne energije što omogućava podizanje stepena iskorišćenja hemijske energije goriva i dizel gorivo). Smanjenje emisija stakleničkih gasova povezanih sa potrošnjom energije može se postići na različite načine, a glavni su energetska efikasnost, racionalno korišćenje energije i kogeneracija.

Brojne studije $i$ istraživačke inicijative koje su preduzele i institucije i akademski zainteresovane strane podržavaju stav da, pored očiglednog potencijala za stvaranje profesionalnih bolesti zbog direktnog kontakta tokom rukovanja hemikalijama, određene hemikalije ugrađene u odeću imaju direktne negativne posledice po svoje krajnje korisnike (UNEP, 2011). Na primer, 2014. godine izveštaj Švedske Hemijske agencije otkrio je da je 10 posto supstanci povezanih sa tekstilom potencijalno zabrinjavajuće za ljudsko zdravlje (www.kemi.se, 2014). Od svih hemikalija proizvedenih širom sveta, približno 25 procenata se koristi u tekstilnoj industriji. Štaviše, samo u tekstilnoj industriji, koja predstavlja preko 40 procenata globalne proizvodnje, Kina koristi oko 42 posto svetskih tekstilnih hemikalija (www.greenpeace.org, 2013). Radnici u tekstilnoj industriji izloženi su hemikalijama koje su povezane sa nekoliko vrsta karcinoma, uključujući rak mozga, rak pluća i rak želuca. Hemijski kontakt sa kožom i udisanje mogu dovesti do drugih ozbiljnih zdravstvenih efekata, dok izlaganje buci takođe predstavlja ozbiljan rizik za radnike. 


\section{Problemi u informacionim tokovima lanaca snabdevanja u modnoj industriji i negativan uticaj na životnu sredinu / \\ Problems in information flows of supply chains in the fashion industry and the negative impact on the environment}

Odevanje je jedna od najvećih industrija u svetskoj ekonomiji, koja godišnje ostvaruje prihode od oko 3 biliona američkih dolara, proizvodi 80 milijardi odevnih predmeta i zapošljava 60 do 75 miliona ljudi širom sveta sa poslovima direktno vezanim sa modom, od čega su dve trećine žene. Industrija je globalna, s lancima snabdevanja (učesnici u trgovini - od proizvođača do potrošača) koji se šire po svim zemljama, a vođeni su uglavnom velikim maloprodavcima i trgovcima koji određuju gde da se proizvodi, šta da se proizvodi i po kojim cenama da se prodaje. Negativni socijalni i ekološki uticaji modne industrije dobro su dokumentovani tokom poslednjih nekoliko decenija, i pokazuju da se ovi uticaji uglavnom javljaju unutar uzvodnog dela lanca snabdevanja. Veoma je važno skrenuti pažnju na probleme $u$ informacionim tokovima $u$ odevnom sektoru $s$ obzirom na negativne uticaje na životnu sredinu, društvo i zdravlje izazvane proizvodima / proizvodnim metodama u lancima vrednosti tekstila. Nedostatak potpunih i transparentnih informacija o tome odakle i ko proizvodi, transformiše i sastavlja materijale, nedostatak transparentnosti u pogledu uticaja praksi i procesa na životnu sredinu i zdravlje ljudi, zajedno sa nedostatkom transparentnosti uslova rada u lancu snabdevanja su ključne praznine. Poboljšanje praćenja informacija je iz tog razloga postalo prioritet za industriju, kako bi se povećala njena sposobnost upravljanja efikasnijim i održivijim lancima snabdevanja (www.unece.org, 2017).

Najveći prerađivač, proizvođač i izvoznik tekstila je Kina i samim tim ima najveću ulogu u globalnim lancima snabdevanja. Prate je uglavnom zemlje azijskog kontinenta. Na satelitskim snimcima Kine i Indije moguće je uočiti duge crvene i plave štrafte, koje zapravo predstavljaju zagađenje crvenom ili plavom bojom koje dolazi iz tekstilne industrije. Ove boje su opasne po zdravlje kada se nađu u slobodnom obliku. Mogu da izazovu kancer, određene iritacije kože i dodatne zdravstvene komplikacije (klima101.rs, 2020).

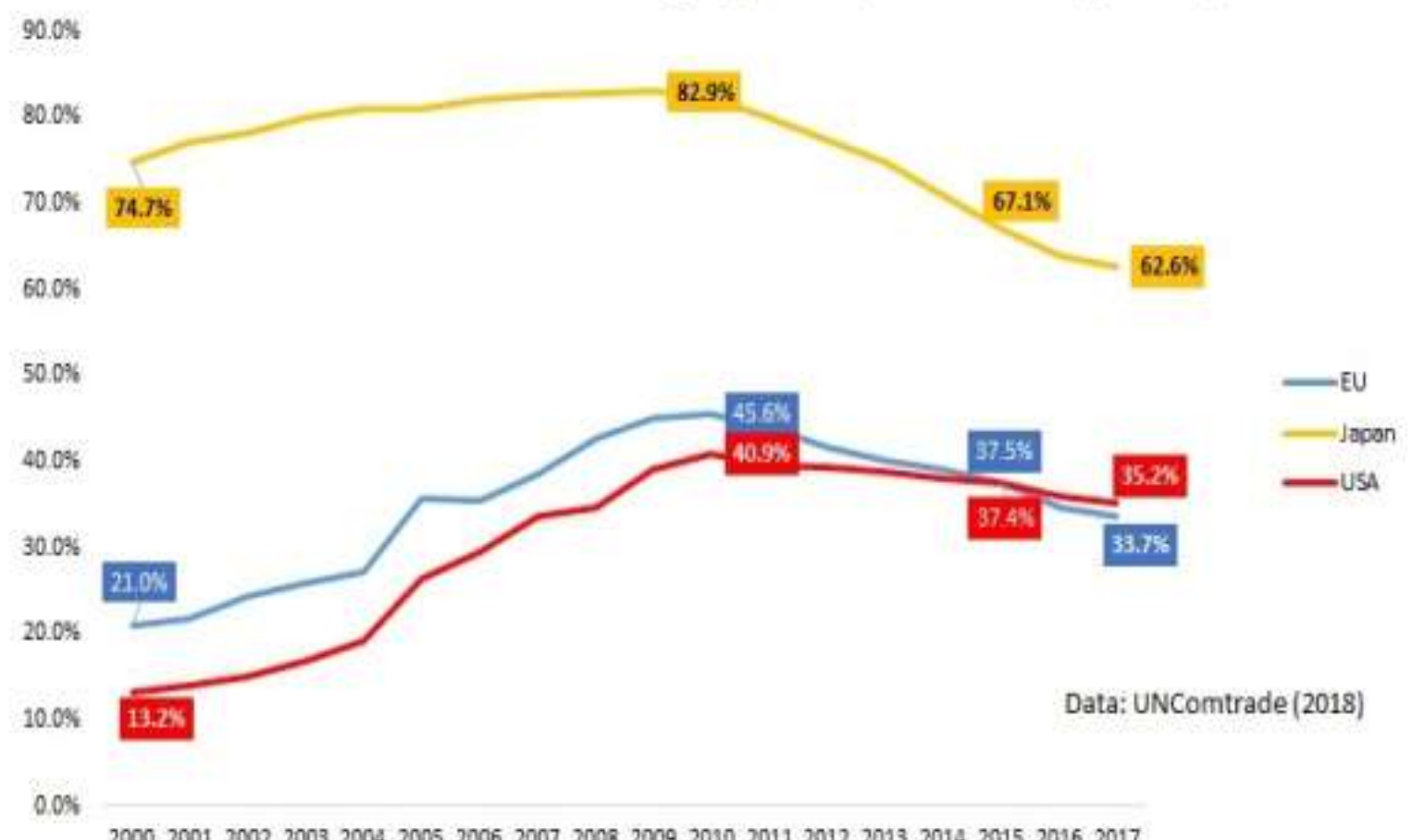

200020012002200320042005200620072008200920102011201220132014201520162017

Grafikon 1 - Udeo Kine na vodećim tržištima odeće Graph 1 - China's share of the leading clothing markets Izvor / Source: https://shenglufashion.com/tag/supply-chain-management/ 


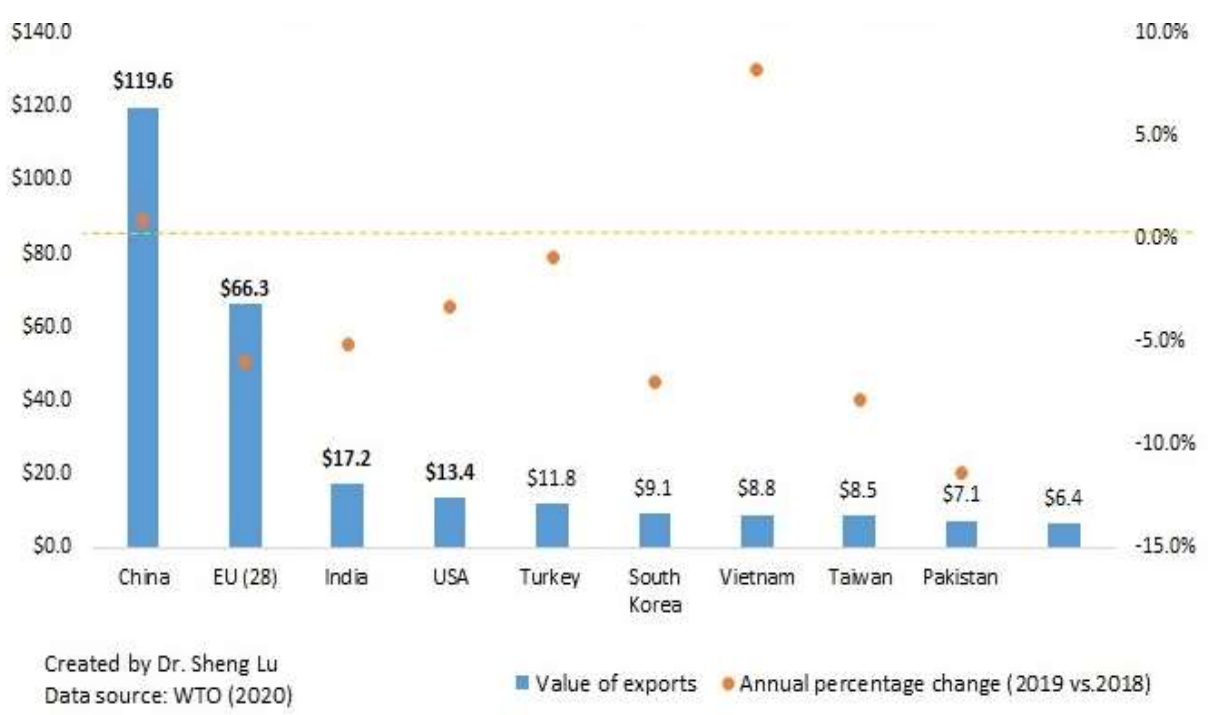

Grafikon 2 - Deset najvećih izvoznika tekstila u 2019. godini

Graph 2 - The ten largest textile exporters in 2019

Izvor / Source: https://shenglufashion.com/tag/supply-chain-management/

\section{REZULTATI I DISKUSIJA / RESULTS AND DISCUSSION}

\section{Akcije koje može sprovesti privreda / Actions that can be carried out by the economy}

Preduzeća često ulažu veliki napor da bi poboljšala odnose sa dobavljačima i unapređenje upravljanja lancem snabdevanja, a sa druge strane izbegavaju ili zanemaruju uvođenje upravljanja ekološki održivim lancem snabdevanja kao način za ostvarivanje bolje konkurentske pozicije. Pojam upravljanja „zelenim“ lancem snabdevanja (engl. Green Supply Chain Management) u sebi spaja dva koncepta upravljanja u jedan - ekološki menadžment i upravljanje lancem snabdevanja (Pavićević i dr., 2020). Slično je i sa preduzećima koja se bave proizvodnjom i prometom tekstila. Zanimljivo je primetiti da većina intervencija koje treba da poboljšaju održivost $u$ praksi proizvodnje tekstila mogu doneti ekonomske koristi za poslovanje kompanija koje se time bave. Ispuštanje zagađujućih materija i otpada, na primer, predstavlja dodatni ekonomski trošak za kompaniju. Zapravo, neefikasni procesi dovode do gubitka skupih hemikalija, rasipanja vode i energije, dok istovremeno dovode do neželjenih varijacija kvaliteta u industrijskoj proizvodnji. Još jedno važno polje istraživanja radi smanjenja hemijskog uticaja na životnu sredinu odnosi se na nivo sirovina koje se koriste $u$ proizvodnji tekstila. Poboljšanje partnerstva između kupaca, farmi i malih i srednjih preduzeča (MSP) u cilju uvođenja inovativne prakse upravljanja zemljištem i vodom, mogle bi smanjiti upotrebu hemikalija i energije i poboljšati kvalitet proizvodnje i zdravlje radnika i stoke. Takođe u ovom slučaju postoji potreba za podacima koji se otkrivaju i prate u vezi sa potrošnjom i poboljšanjem performansi. Ovo bi trebalo da uključuje upotrebu softvera i alata za fizičko praćenje i mapiranje životinja i žetve uključene u održive i etičke prakse. Štaviše, dobra praksa u skladištenju ugljen-dioksida, sa velikim proširenjem plantaža drveća, može predstavljati akciju korporativne društvene odgovornosti (CSR) za velika preduzeća, dok istovremeno pomaže poljoprivrednicima da poboljšaju zemljište upravljanje i smanjenje erozije tla, utičući na kvalitet proizvodnje. Takođe, velike kompanije i vlade (koordinisane akcije i istraživački programi) mogu da pomognu MSP i farmama da eksperimentišu koristeći novu tehnologiju i metode praćenja kako bi smanjili hemikalije u lancu snabdevanja.

U Tabeli 1 prikazane su koristi od primene čistijih proizvodnih procesa na primeru First Textile, kompanije sa sedištem u Turskoj koja se bavi proizvodnjom pletenog tekstila, prediva, obojenog i štampanog tekstila.

Zemlje u razvoju, kao što je naša, može da koristi pomoć velikih kompanija u projektima kroz Mehanizam čistog razvoja (CDM - Clean Development Mechanism) koji pomažu da se smanji emisija štetnih gasova koji stvaraju efekat staklene baste (Cvijić i dr., 2013).

Evropska komisija kao najvažnije zadatke u zaštiti životne sredine navodi čistije tehnologije, inovacije i istraživanja u cilju smanjenja emisije štetnih gasova. Evropska unija sebe smatra liderom u onome što se naziva cirkularna ekonomija. „Evropski zeleni dogovor" je doneo novi Akcioni plan za cirku- 
larnu ekonomiju, a on je usvojen u martu ove godine (greenfest.rs, 2020). Naglasak je na održivom korišćenju resursa, pre svega u oblastima tekstila i građevinarstva (MPCES, 2020). Cirkularna ekonomija je pristup koji menja funkciju resursa u privredi. Otpad iz fabrika može da se iskoristi u nekom drugom proizvodnom procesu, a proizvodi se mogu popraviti, unaprediti ili ponovo iskoristiti umesto da završe na deponiji. Ovaj pristup je alternativa postojećem, neodrživom, jednosmernom pristupu. Cirkularna ekonomija ima za cilj stvaranje društva u kom je stvaranje otpada svedeno na minimum sa visokim nivoom ponovnog iskorišćavanja resursa, novih poslovnih modela i reciklažnih tehnologija (bfpe.org, 2017). Proces prelaska sa linearne na cirkularnu ekonomiju zahteva odgovarajuće socijalne, kulturne, finansijske, pravne i političke okvire (Milićević i dr., 2020). Akcioni plan predviđa vrlo brzo i razvoj „EU strategije za tekstil“. Pored toga, usvojena Direktiva (EU) 2018/851 o izmeni Okvirne direktive 2008/98/EZ za upravljanje otpadom predviđa obavezu da, zaključno sa 1. januarom 2025. godine, sve države članice uvedu odvojeno prikupljanje tekstilnog otpada $\mathrm{i}$ istovremeno obezbede da ono što je prikupljeno ne završi u spalionicama ili na deponijama (greenfest.rs, 2020).

Tabela 1 - Koristi od primene čistijih proizvodnih procesa na primeru iz prakse

Table 1 - Benefits from the application of cleaner production processes on a practical example

\begin{tabular}{|l|c|c|c|}
\hline $\begin{array}{l}\text { Korist za životnu } \\
\text { sredinu }\end{array}$ & $\begin{array}{c}\text { Troškovi (investicioni } \\
\text { i operacioni) }\end{array}$ & Godišnja ušteda & Vreme povratka novca \\
\hline $\begin{array}{l}\text { Smanjenje potrošnje } \\
\text { vode, energije i } \\
\text { hemikalija }\end{array}$ & O USD & $32.370-58.340$ USD & Veoma brzo \\
\hline $\begin{array}{l}\text { Smanjenje potrošnje } \\
\text { vode i soli }\end{array}$ & 20.000 USD & 57.680 USD & 3 meseca \\
\hline $\begin{array}{l}\text { Smanjenje potrošnje } \\
\text { pare i energije, } \\
\text { Kontrola zagađenja } \\
\text { vazduha }\end{array}$ & 28.820 USD & 513.000 USD & 1 godina \\
\hline
\end{tabular}

Izvor / Source: www.unece.org (2017)

\section{Životni ciklus odevnih predmeta i navike potrošača: moć pojedinca / \\ The life cycle of clothing and consumer habits: the power of the individual}

Modni trendovi se brzo menjaju i njihovo praćenje i reagovanje na njih prave sve veći problem. Prema podacima Ekonomske komisije Ujedinjenih nacija za Evropu, modna industrija proizvodi čak 10 $\%$ ukupne svetske emisije $\mathrm{CO}_{2}$, što je pet puta više od avio-industrije. Pored toga, modna industrija odgovorna je i za $20 \%$ otpadnih voda. Ova industrija u velikoj meri zavisi od fizičkog rada i zapošljava oko 40 miliona ljudi širom sveta koji su plaćeni manje od minimalca i rade u nehumanim uslovima. $U$ većini su zaposlene žene, a često se otkrije da su zaposlena i deca. Nije problem samo proizvodnja odeće, već i njeno odlaganje nakon što se prestane nositi. Materijali koji nisu biorazgradivi mogu da se održe 200 godina na deponiji, odeća ne završava samo na đubrištu već i u moru, a majice koje su od poliestera ispuštaju mikroplastiku svaki put kada se operu (klima101.rs, 2019).

Da li pojedinac može da doprinese smanjenju zagađenja tekstilom i smanjenju zagađenja uopšte? Možda je rešenje insistiranje na sporoj, umesto na brzoj modi. Pokušati da se kupuje samo ono što će se zaista nositi i to više puta. Ako je moguće, kupovati kvalitetnije proizvode, iako su skuplji, umesto jeftinijih, a lošijeg kvaliteta. Modna industrija živi od toga da se trendovi stalno menjaju i postoji pritisak na potrošače da stalno kupuju nove stvari, koje im, u velikoj meri, i nisu potrebne. Prate se novi trendovi, dok se stara odeća odbacuje i završi na deponiji. Od 80 milijardi odevnih predmeta koji se proizvedu u jednoj godini, 80 \% će završiti na deponiji. Kako se boriti protiv ovog? Spora moda je kontrakultura brzoj modi. Zalaže se za kupovinu odeće u second hand prodavnicama, podržava male lokalne proizvođače, prepravke već kupljene odeće i kupovinu kvalitetnije odeće koja ima duži vek trajanja. Zbog manje proizvodnje spora moda nudi kvalitetniju odeću koja je pravljena u fer uslovima i ostavlja manje otpada. Organizacija za ekonomsku saradnju i razvoj (OECD) je 2011. godine sprovela istraživanje o ponašanju potrošača u životnoj sredini. Informacije su prikupljene iz više od 12.000 domaćinstava u Australiji, Kanadi, Čileu, Francuskoj, Izraelu, Japanu, Koreji, Holandiji, Španiji, Švedskoj i Švajcarskoj i otkriveno je da su ekološki stavovi bitni i vlade mogu da imaju ulogu u njihovom formiranju i oblikovanju. Shodno tome, složeni skup faktora podupire odluke i navike ljudi, uključujući 
znanje, dostupnost informacija, poverenje, brige suseda, nivo zaštite životne sredine aktivizam, kao i obrazovanje, prihod i vlasnički status. Nekoliko nalaza ove studije sugeriše da dobro osmišljene informativne kampanje i obrazovni programi mogu promeniti ponašanje. Štaviše, iako je istraživanje potvrdilo da cene i troškovi mogu imati ogroman uticaj na odluke domaćinstava, takođe je otkrilo ukupnu spremnost da budu zeleni (ekološki svesni) i da plate više za ekološki prihvatljive izbore.

Istraživanje sprovedeno u Srbiji, 2020. godine imalo je kao cilj da otkrije koliko je visoko razvijena svest o štetnim uticajima modne industrije kod potrošača. Rezultati pokazuju da ne postoji visoko razvijena svest o štetnim uticajima trgovine tekstilom, odnosno modne industrije kod potrošača. Tek svaki treći ispitanik zna da je ova industrija veliki potrošač energije i vode, a polovina je upoznata sa nepovoljnim uslovima u kojima se proizvodi odeća.

Tabela 2 - Ispitanici, podeljeno po godištu, koji su potvrdno odgovorili da su upoznati sa uslovima $i$ posledicama modne industrije - procenti

Table 2 - Respondents, divided by year, who answered affirmatively that they were familiar with the conditions and consequences of the fashion industry - percentages

\begin{tabular}{|l|c|c|c|}
\hline & $\begin{array}{c}18-30 \\
\text { god. }\end{array}$ & $\begin{array}{c}31-45 \\
\text { god. }\end{array}$ & $\begin{array}{c}45 \text { i više } \\
\text { god. }\end{array}$ \\
\hline Radni uslovi & $45,9 \%$ & $58,2 \%$ & $54,2 \%$ \\
\hline $\begin{array}{l}\text { Potrošnja } \\
\text { energije i } \\
\text { vode }\end{array}$ & $30,5 \%$ & $39,6 \%$ & $52,8 \%$ \\
\hline
\end{tabular}

Izvor / Source: (greenfest.rs, 2020)

Ovo istraživanje je 2020. godine sproveo Centar za unapređenje životne sredine pod radnim nazivom Analiza istraživanja o životnom ciklusu odevnih predmeta u Republici Srbiji kao deo publikacije Vreme je za novu modu!. Ono pokazuje veliku važnost informisanja potrošača i podizanje nivoa znanja i svesti o negativnim uticajima brze mode, odnosno lošeg uticaja gomilanja tekstila i njegovog odlaganja na životnu sredinu.

\section{ZAKLJUČAK / CONCLUSION}

Pored drugih zagađivača životne sredine i proizvodnja i promet tekstila i modna industrija koja to prati su veliki zagađivači životne sredine i opasni kako za zaposlene u proizvodnji tako i za krajnje korisnike- potrošače. Međutim, ovaj zagađivač nije dovoljno akcetovan, kao neki drugi, iako je njegov uticaj na životnu sredinu veliki. Većina hemikalija i pomoćnih tečnosti koje se koriste u proizvodnji i daljoj preradi završi u otpadnim vodama, a velika količina kupljene odeće vrlo brzo završi ili u spalionicama ili na deponijama. Takođe, ova industrija je veliki potrošač energije: odeća, obuća i tekstil za domaćinstvo zauzimaju četvrto mesto u korišćenju resursa vode, drugo mesto u korišćenju zemljišta i peto po količini emitovanja gasova sa efektom staklene bašte.

Jedan od problema je i nedostatak transparentnih informacija o tome šta se dešava u lancu snabdevanja na putu robe ka potrošačima i kod proizvođača i kod dalje obrade materijala. Preduzeća više pažnje posvećuju unapređenju svojih lanaca snebdevanja nego ekološkim merama koje mogu i moraju da uvedu. Privreda ima dužnost, ali i korist da uvede mere za štetne uticaje koje modna industrija donosi životnoj sredini i za smanjenje potrošnje energije. Smanjenje emisija stakleničkih gasova povezanih sa potrošnjom energije može se postići na različite načine, a glavni su energetska efikasnost, racionalno korišćenje potrošnje energije i kogeneracija. Promena sadašnje linearne ekonomije $u$ cirkularnu je zadatak svih organizacija, a ne samo preduzeća koja se bave proizvodnjom i prodajom tekstila. Nivo zagađenja koji trgovina tekstilom ostavlja iza sebe nije dovoljno poznat među potrošačima, što i istraživanja pokazuju, a vlade i privreda mogu uticati na ekološku svest potrošača. U mnogim zemljama se javljaju pokreti koji afirmišu sporu modu, odnosno drugačiji pogled na konzumaciju odeće i samim tim smanjenje količina koje završe na deponijama.

\section{LITERATURA / REFERENCES}

[1] Chemicals in textiles. Swedish Chemical Agency, (2014). Preuzeto 15.03.2021 sa: https://www.kemi.se/download/18.6df1d3df171 c243fb23a98f3/1591454110491/rapport-6-14chemicals-in-textiles.pdf

[2] Chemicals Substitution in Textile Industry: Imp/ementing Chemical Policies Into the Textile Supply Chain, (2013). Preuzeto od:

http://www.greenpeace.org/china/Global/china/ publications/others/2013/20130325GPENG.pdf

[3] Cvijić, L., Jovanović, L., Tomić, A., Radosavljević, M., Anđelković, M. (2013), Napredak Republike Srbije u pripremi CDM projekata, Ecologica, 20 (69), 67-72.

[4] Domaća inovacija sprečava bojenje veša i zagađivanje reka, (2020). Preuzeto 12.03.2021 sa: https://klima101.rs/inovacija-hvatac-tekstilnihboja-dr-knight/ 
[5] Emission Scenario Document on Textile Finishing Industry, (2004). Preuzeto 12.03.2021 sa: http://www.oecd.org/officialdocuments/publicdis playdocumentpdf/?cote=env/jm/mono(2004) 12 \&doclanguage $=\mathrm{en}$

[6] Kaye, L. (2013). Clothing to dye for: the textile sector must confront water risks. The Guardian. Preuzeto od:

https://www.theguardian.com/sustainablebusiness/dyeing-textile-sectorwater-risksadidas

[7] Mapa puta za cirkularnu ekonomiju u Srbiji (MPCES), (2020). Ministarstvo zaštite životne sredine Republike Srbije, Preuzeto 12.03.2021. sa: https://www.rs.undp.org/content/serbia/sr/home /library/mdg/roadmap-for-circular-economy-inserbia.html

[8] Milićević, V., Arsić, Lj., Premović, J., Milićević, Z., Vidosavljević, S., Đokić, N., (2020), Nove tehnologije i inovacije: put do cirkularne ekonomije, Ecologica, 27 (100), 675-682.

[9] Osnove cirkularne ekonomije, (2017), preuzeto 12.03.2021. sa: https://bfpe.org/wpcontent/uploads/2017/09/Osnove-cirkularneekonomije.pdf
[10] Pavićević, A., Vuković, A., Cvijić, L. (2020), Ekološki aspekti lanaca snabdevanja - pojam ozelenjavanja, Ecologica, 27 (100), 655-662.

[11] Spora moda i klimatske promene, (2019). Preuzeto 12.03.2021 sa: https://www.klima101. rs/spora-moda-klimatske-promene/

[12] The Chemicals in Products Project: Case Study of the Textiles Sector prepared by UNEP, DTIE / Chemicals Branch. (2011), UNEP, 2011. Preuzeto 15.03.2021 sa:

http://www.health.gov.vc/health/images/PDF/ci p_textile_case_study_report_21_feb_2011.pdf

[13] Transparency in textile value chains in relation to the environmental, social and human health impacts of parts, components and production processes, (2017). Preuzeto 12.03.2021 sa: https://www.unece.org/fileadmin/DAM/trade/Pu blications/ECE-TRADE-439ETEXTILE4SDG12.pdf

[14] Vreme je za NOVU MODU! Analiza istraživanja o životnom ciklusu odevnih predmeta u Republici Srbiji, (2020). Preuzeto 12.03.2021. sa: https://greenfest.rs/publikacije/Analiza_istraziva nja_o_zivotnom_ciklusu_odevnih_predmeta_u _RS.pdf. 